\title{
IMPACT OF THE NEW STAGING TNM AJCC ON THE EVALUATION OF PATIENTS WITH BREAST CANCER
}

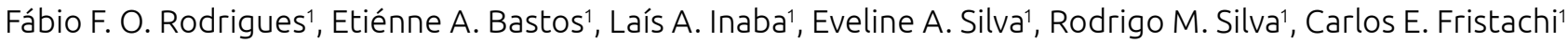

IInstituto do Câncer Doutor Arnaldo Vieira de Carvalho - São Paulo (SP), Brazil.

Objectives: To evaluate the importance of the incorporation of the biological markers on the TNM 8th Edition to improve the staging of patients attended on the Dr Arnaldo Vieira Cancer Institute (ICAVC) from 2006 to 2012. Methods: A longitudinal study was performed, descriptive type, retrospective, of patients with breast carcinoma attended at ICAVC in Sao Paulo; data were analyzed on the data base of Microsoft Excel@. Results: Were evaluated 119 patients; of wich 58\% presented changes related to staging accomplished in 2012, of these $52 \%$ presented changes with upstaging, $17.4 \%$ downstaging and 30.6\% remained with the same clinical staging. Conclusion: With that study, we observed that most patients presented modification on the clinical staging, wich shows the importance of the incorporation of the biological markers to improve the related knowledge of the prognoses and treatment of breast cancer. 